\title{
Physical exercise promotes astrocyte coverage of microvessels in a model of chronic cerebral hypoperfusion
}

Marina Leardini-Tristão ${ }^{1,2}$, Giulia Andrade ${ }^{1,2}$, Celina Garcia ${ }^{3}$, Patrícia A. Reis ${ }^{1}$, Millena Lourenço ${ }^{1}$, Emilio T. S. Moreira ${ }^{1}$, Flavia R. S. Lima ${ }^{3}$, Hugo C. Castro-Faria-Neto ${ }^{1}$, Eduardo Tibirica ${ }^{2,4}$ and Vanessa Estato ${ }^{1,2^{*}}$

\begin{abstract}
Background: Brain circulation disorders such as chronic cerebral hypoperfusion have been associated with a decline in cognitive function during the development of dementia. Astrocytes together with microglia participate in the immune response in the CNS and make them potential sentinels in the brain parenchyma. In addition, astrocytes coverage integrity has been related to brain homeostasis. Currently, physical exercise has been proposed as an effective intervention to promote brain function improvement. However, the neuroprotective effects of early physical exercise on the astrocyte communication with the microcirculation and the microglial activation in a chronic cerebral hypoperfusion model are still unclear. The aim of this study was to investigate the impact of early intervention with physical exercise on cognition, brain microcirculatory, and inflammatory parameters in an experimental model of chronic cerebral hypoperfusion induced by permanent bilateral occlusion of the common carotid arteries (2VO).

Methods: Wistar rats aged 12 weeks were randomly divided into four groups: Sham-sedentary group (Sham-Sed), Sham-exercised group (Sham-Ex), 2VO-sedentary group (2VO-Sed), and 2VO-exercised group (2VO-Ex). The early intervention with physical exercise started 3 days after $2 \mathrm{VO}$ or Sham surgery during 12 weeks. Then, the brain functional capillary density and endothelial-leukocyte interactions were evaluated by intravital microscopy; cognitive function was evaluated by open-field test; hippocampus postsynaptic density protein 95 and synaptophysin were evaluated by western blotting; astrocytic coverage of the capillaries, microglial activation, and structural capillary density were evaluated by immunohistochemistry.

Results: Early moderate physical exercise was able to normalize functional capillary density and reduce leukocyte rolling in the brain of animals with chronic cerebral hypoperfusion. These effects were accompanied by restore synaptic protein and the improvement of cognitive function. In addition, early moderate exercise improves astrocytes coverage in blood vessels of the cerebral cortex and hippocampus, decreases microglial activation in the hippocampus, and improves structural capillaries in the hippocampus.

(Continued on next page)
\end{abstract}

\footnotetext{
* Correspondence: estato@ioc.fiocruz.br; vanessaestato@gmail.com

'Laboratory of Immunopharmacology, Oswaldo Cruz Foundation, Av. Brasil,

4365, Manguinhos, Rio de Janeiro 21040-900, Brazil

2Laboratory of Cardiovascular Investigation, Oswaldo Cruz Foundation, Rio de Janeiro, Brazil

Full list of author information is available at the end of the article
}

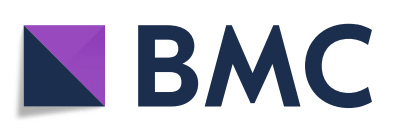

(c) The Author(s). 2020 Open Access This article is licensed under a Creative Commons Attribution 4.0 International License, which permits use, sharing, adaptation, distribution and reproduction in any medium or format, as long as you give appropriate credit to the original author(s) and the source, provide a link to the Creative Commons licence, and indicate if changes were made. The images or other third party material in this article are included in the article's Creative Commons licence, unless indicated otherwise in a credit line to the material. If material is not included in the article's Creative Commons licence and your intended use is not permitted by statutory regulation or exceeds the permitted use, you will need to obtain permission directly from the copyright holder. To view a copy of this licence, visit http://creativecommons.org/licenses/by/4.0/. The Creative Commons Public Domain Dedication waiver (http://creativecommons.org/publicdomain/zero/1.0/) applies to the data made available in this article, unless otherwise stated in a credit line to the data. 
(Continued from previous page)

Conclusions: Microcirculatory and inflammatory changes in the brain appear to be involved in triggering a cognitive decline in animals with chronic cerebral ischemia. Therefore, early intervention with physical exercise may represent a preventive approach to neurodegeneration caused by chronic cerebral hypoperfusion.

Keywords: Exercise, Cerebral hypoperfusion, Neuroinflammation, Glial cells, Microcirculation

\section{Background}

Dementia is a neurodegenerative disease with a progressive impairment of cognition and behavioral changes that may be preceded or accompanied by loss of neurons, neuroinflammation, and oxidative stress $[1,2]$. Brain circulation disorders, such as chronic cerebral hypoperfusion, have been associated with a decline in cognitive function in elderly people and during the development of dementia $[3,4]$. Micro- and macrovascular changes are also related to the neurodegenerative process and may occur before the onset of dementia [5]. Vascular dementia highlights the importance of vascular contributions to cognitive impairment and represents the second most common form of dementia following Alzheimer's disease [6].

In the last few decades, animal models have been used to study alterations and consequences of chronic reduction on cerebral blood flow (CBF) that may occur in neurodegenerative disease. The permanent bilateral occlusion of the common carotid arteries in rats (or 2vessel occlusion, 2VO) is a cerebral hypoperfusion model that impacts the regions of the brain associated with learning and memory processes, such as the cortex and hippocampus [7]. The chronic phase of the 2VO model, between the eighth and twelfth weeks after the procedure, more closely resembles the decrease in CBF in human aging and dementia. In this phase of the model, the neurodegenerative process is more extensive; therefore, it is the most used phase for the study of dementia [4].

Astrocytes together with microglia participate in the immune response in the CNS. The location of these cells, in or near the blood-brain barrier (BBB), makes them potential sentinels in the brain parenchyma. Astrocytes play an important role in communicating with blood vessels, being involved in the maintenance of the $\mathrm{BBB}$ and $\mathrm{CBF}$, providing for the nutrition of neurons, and promoting vasodilation in response to neuronal activation [8]. Microglia are the most common resident immune cells, which represent the first-line of inflammatory response in brain tissue and are generally activated during infections, lesions, or degenerative diseases [9]. Microglia activation in response to injury commonly involves morphological changes leading to transformation from a ramified to amoeboid form [10]. Activation also induces the release of proinflammatory cytokines and chemokines, which promotes the infiltration of circulating leukocytes into the brain, leading to the chronic inflammatory process present in neurodegenerative diseases [11].
Experimental and clinical studies have shown that the acute phase after cerebral ischemia is a critical window for the impairment of neuronal plasticity. Treatment during this period can trigger and promote neuroprotective mechanisms that will assist in the recovery of neuronal functions [12-15]. Among new therapeutic strategies being pursued to minimize cognitive damage, physical exercise has been shown to support brain health and function, with an impact on neurogenesis $[16,17]$, reducing neuroinflamation $[14,18]$ and oxidative stress $[14,19]$. Moreover, regular physical exercise is able to improve cognitive function in animals [20,21], and in adult and elderly populations [22-24].

This paper describes a new approach to the neuroprotective role of physical exercise in chronic hypoperfusion, a common feature of dementia. It is possible that exercise modulates the interaction between glial cells and brain microcirculation, but this hypothesis has not yet been fully investigated. Thus, using the $2 \mathrm{VO}$ model, we investigated the impact of early moderate exercise as a therapeutic strategy on brain microcirculation, neuroinflammation, and astrocytic coverage of brain vessels.

\section{Methods}

Animals and ethics statement

Fifty-eight male Wistar rats (Oswaldo Cruz Foundation Animal Facilities, Rio de Janeiro, Brazil), 12 weeks old, were housed under controlled temperature $\left(21 \pm 2{ }^{\circ} \mathrm{C}\right)$ and light (12 h light/dark cycles) conditions and were allowed free access to water and standard rat chow. All experiments were conducted in accordance with internationally accepted principles for the care and use of laboratory animals and were approved by the Animal Ethics Committee of the Oswaldo Cruz Foundation (protocol number L-002/2016).

\section{Experimental design}

We analyzed the effects of physical exercise on cerebral hypoperfusion in the two-vessel occlusion (2VO) experimental model. We chose the cerebral hypoperfusion model because it is a validated and representative model of changes in the cerebral blood flow of aging without, therefore, including the bias of the physical limitations of aging in the performance of physical exercise [4]. Animals were randomly assigned to the following four experimental groups: (1) subjected to cerebral hypoperfusion and 
exercise (2VO-Ex; $n=15)$; (2) subjected to cerebral hypoperfusion and non-exercised (sedentary) (2VO-Sed; $n=$ 15); (3) subjected a sham procedure and exercise (ShamEx; $n=12$ ); and (4) subjected a sham procedure and nonexercised (sedentary) (Sham-Sed; $n=11$ ). The animals in the sham groups were subjected to the same surgical procedure without ligation of the left and right common carotid arteries.

Three days after surgery, the exercised groups performed maximal exercise testing (MET). The exercise protocol then started $24 \mathrm{~h}$ following MET. After completing 12 weeks of a moderate physical exercise protocol, the animals underwent cognitive, hemodynamic, microcirculatory, and inflammatory assessments.

\section{Two-vessel occlusion (2VO) surgical procedure}

In order to promote a global and chronic cerebral hypoperfusion, rats were anesthetized intraperitoneally (i.p.) with ketamine $(90 \mathrm{mg} / \mathrm{kg})$ and xylazine $(10 \mathrm{mg} / \mathrm{kg})$, and underwent $2 \mathrm{VO}$ surgery as previously described (Farkas et al. 2004). Briefly, a ventral incision was made in the midline of the neck using a scalpel to expose the left and right common carotid arteries, which were gently separated from the vagus nerve. Animals in the $2 \mathrm{VO}$ group had both vessels permanently occluded with 6-0 silk suture. The sham groups were subjected to the same procedure without occlusion of the carotid arteries. After surgery, the animals received subcutaneous injections of an anti-inflammatory drug, ketoprofen $(1 \mathrm{mg} / \mathrm{kg} /$ day for 3 days) and an antibiotic, meropenem $(10 \mathrm{mg} / \mathrm{kg}$, single dose). The animals were kept in individual cages until the end of the experimental protocol to avoid stress $[14,25]$.

\section{Aerobic exercise training protocol}

Before surgery, all the animals were adapted to a treadmill for rats (Model HT 2.0 Hectron Fitness Equipment, Rio de Janeiro, Brazil) by running at a speed of $10 \mathrm{~m} /$ min for $10 \mathrm{~min}$ over a period of 3 days. Then, the 3 days after surgery the MET was performed to establish the appropriate training intensity [26]. The MET began at a speed of $10 \mathrm{~m} / \mathrm{min}$; the speed was then increased by 3 $\mathrm{m} / \mathrm{min}$ every $3 \mathrm{~min}$ until the animals reached exhaustion and remained on the shock grid for more than $5 \mathrm{~s}$. For each MET trial, time to exhaustion, maximal speed, and maximal distance were recorded. Maximal speed was used to determine the training intensity for the duration of the investigation, which was $60 \%$ of the MET. The MET was also performed on the sixth week of exercise to adjust the intensity of the protocol.

The physical exercise consisted of 30-min sessions, 3 times a week over 12 weeks at $60 \%$ of the maximal speed, which occurred between 8:00 and 10:00 am. Twenty-four hours after the last exercise for the exercised group or sedentarism for the sedentary group, the animals underwent additional procedures for cognitive function, hemodynamic parameter levels, microcirculatory, and neuroinflammatory alterations.

\section{Hemodynamic assessment}

In order to monitor blood pressure, systolic blood pressure (SBP) was assessed in conscious animals one day before $2 \mathrm{VO} /$ sham surgery (baseline measurement), $48 \mathrm{~h}$ after $2 \mathrm{VO} /$ sham surgery and after 12 weeks of exercise or sedentarism using a computerized tail-cuff plethysmography system (BP-2000; Visitech Blood Pressure Analysis System, Apex, NC, USA). The animals were adapted to the apparatus for three consecutive days prior to undergoing their baseline measurements.

\section{Open-field test}

At the end of 12 weeks of exercise, cognitive function was investigated by an open-field test. Habituation to an open field was carried out as described by Vianna and coworkers [27], and consists of quantitatively assessing the exploratory and locomotor activities, as well as the habituation memory of the animals. Briefly, animals were gently placed in the center of an open box $(50 \mathrm{~cm}$ high, $50 \mathrm{~cm}$ wide, $39 \mathrm{~cm}$ deep) with the floor divided into a grid and allowed to explore the arena for 5 min (training session). After $24 \mathrm{~h}$ the animals were submitted to a similar open-field session (test session). Crossing of the gridlines and rearing (rearing up on the hind legs) performed in both sessions were counted.

\section{Intravital microscopy imaging}

Brain microcirculation of all groups of animals was observed via cranial window imaging, and the functional capillary density and leukocyte-endothelium interactions were evaluated by fluorescence intravital video microscopy as previously described $[28,29]$. Briefly, the animals were anesthetized with ketamine $(90 \mathrm{mg} / \mathrm{kg}$, i.p.) and xylazine $(10 \mathrm{mg} / \mathrm{kg}$, i.p.) and fixed in a stereotaxic frame. Then, their left parietal bones were exposed via midline skin incisions, and a cranial window on the right parietal bone $(5 \mathrm{~mm}$ diameter, between the coronal and lambdoid sutures) was created with a high-speed drill. The dura mater and arachnoid membranes were subsequently excised and withdrawn to expose the cerebral microcirculation, after which the cranial windows were suffused with artificial cerebrospinal fluid (132 mM $\mathrm{NaCl}, 2.95 \mathrm{mM} \mathrm{KCl}, 1.71 \mathrm{mM} \mathrm{CaCl} 2,0.64 \mathrm{mM} \mathrm{MgCl} 2$, $24.6 \mathrm{mM} \mathrm{NaHCO} 3,3.71 \mathrm{mM}$ dextrose, and $6.7 \mathrm{mM}$ urea, $\mathrm{pH} 7.4$, at $37^{\circ} \mathrm{C}$ ).

The visualization of the brain microvascular surface was facilitated by intravenous administration of $0.1 \mathrm{~mL}$ of $2 \%$ fluorescein isothiocyanate (FITC)-labeled dextran using a microscope and epi-illumination (Olympus BX150WI, NY, USA) outfitted with a fluorescent light 
source (460 to $490 \mathrm{~nm}$ using a $520 \mathrm{~nm}$ emission filter). Microscopic images were subsequently acquired, and capillaries were counted using Cell Sens Standard 1.9 software. The functional capillary density, defined as the total number of spontaneously perfused capillaries per square millimeter of surface area, was determined in the random microscopic field of view over a 4-min period [29].

Leukocytes were fluorescently labeled by intravenous administration of rhodamine $6 \mathrm{G}(0.3 \mathrm{mg} / \mathrm{kg})$ and observed through the cranial window. Adherent leukocytes were defined as the number of leukocytes adhered to the venular endothelium for a period of $30 \mathrm{~s}$ or longer and expressed as cell number/min/100 $\mu \mathrm{m}$. Leukocytes were considered rolling on the vessel wall if they moved at a slower rate than circulating erythrocytes, and expressed in cells/min. Brain surface venules with diameters ranging from 50 to $100 \mu \mathrm{m}$ were analyzed [29].

\section{Tissue processing}

After intravital microscopy, rats were euthanized by pentobarbital overdose (150 mg/kg, i.p.). The brain was dissected, and the hippocampus and left hemisphere cortex regions were stored in the freezer at $-80{ }^{\circ} \mathrm{C}$ for subsequent western blot analysis. For immunohistochemical analysis, 5 animals per group were anesthetized with ketamine and xylazine (90 and $10 \mathrm{mg} / \mathrm{kg}$ i.p., respectively) and transcardially perfused with $0.9 \%$ saline followed by $4 \%$ paraformaldehyde and the brains were then removed and maintained in paraformaldehyde solution.

\section{Western blot analysis}

Protein levels of synaptophysin and postsynaptic density protein 95 (PSD-95) in the hippocampus were determined by western blot analysis. The hippocampus was homogenized in $50 \mathrm{mM}$ Tris, $\mathrm{pH} 8.0$, containing 150 $\mathrm{mM} \mathrm{NaCl}, 1 \mathrm{mM}$ EDTA, 1\% Triton X-100, 0.5\% sodium deoxycholate, $0.1 \%$ SDS, and protease inhibitor cocktail (Complete Mini Protease Inhibitor Cocktail; Roche Diagnostics, IN, USA). Homogenates were incubated for 30 min on ice, sonicated for $3 \mathrm{~min}$, and centrifuged at $10000 \times g$ at $4{ }^{\circ} \mathrm{C}$. The supernatant was collected, and the protein concentration was measured using bicinchoninic acid method, with bovine serum albumin (BSA) as the standard (BCA Protein Assay Kit, Thermo Scientific, Waltham, MA, USA). Then, $50 \mu \mathrm{g}$ of protein per lane was separated on a $12 \%$ SDS-PAGE gel and transferred to a nitrocellulose membrane (BioRad Laboratories, Munich, Germany). After blocking with 5\% BSA (Sigma Aldrich, St. Louis, MO, USA), the membranes were incubated overnight at $4{ }^{\circ} \mathrm{C}$ with antibodies to synaptophysin and PSD-95 (1:500 and 1:5000 respectively; Abcam) followed by a secondary antibody (1:20000). Beta actin (1:10000; Abcam) was used as a loading control. The data were obtained by Odyssey software (Li-Cor Biosciences, Lincoln, NE, USA).

\section{Immunohistochemistry}

For immunohistochemistry analysis, brains were quickly excised after perfusion-fixation as described above and serially sectioned at $50 \mu \mathrm{m}$. The sections were washed with PBS and incubated with 10\% NGS diluted in PBS with $0.3 \%$ Triton X-100 for $90 \mathrm{~min}$. They were then incubated with antibodies to the glial fibrillary acidic protein (GFAP, Dako; 1:400) and the ionized calcium-binding adaptor molecule 1 (Iba1, Wako; 1:200) or with biotinylated IB4 (Vector; 1:100) overnight at $4{ }^{\circ} \mathrm{C}$, then washed again with PBS and incubated with secondary antibodies conjugated with Alexa Fluor 488 or 546 (1:400) or streptavidin-Cy3 (1:400) for $2 \mathrm{~h}$. The sections were counterstained with DAPI and coverslips were mounted with fluoromount. Negative controls were performed with non-immune rabbit IgG. Slices were imaged using a confocal microscope (Leica TCS-SP5) equipped with a 63X NA 1.40 oil-immersion objective. We were careful to apply the same selection criteria to all cuts. Initially, we located the CA1 region of the hippocampus and then we located the parietal cortex. Image processing was performed using Fiji, ImageJ software.

For microglial morphology analysis, the ImageJ Sholl Analysis tool was used. This is a quantitative analysis method commonly used in neuronal studies to characterize the morphological characteristics of an imaged neuron. Using Sholl analysis, a mathematical algorithm of the program called "branching index" is used to analyze neuronal morphology. This index compares the difference in the number of intersections make consecutive circles of the Sholl analysis in relation to the distance of the neuronal sum. In this study, microglial processes were quantified as a number of intersections from 2 to $40 \mu \mathrm{m}$ from the sum and total number of intersections within the analysis circles, representing the total branch of the microglia.

For the analysis of the cerebral microvascular angioarchitecture, the AngioTool program was used (https://ccrod.cancer.gov/confluence/display/ROB2/Downloads) to determine the total length of the brain capillaries on each image obtained by confocal microscopy. AngioTool is a validated source for measuring vascular networks [30] and has already been described in analyses of murine brain and retinal angiogenesis [31, 32].

\section{Statistical analysis}

The results are expressed as the mean \pm standard error of the mean (SEM) for each group. Between-group statistical comparisons were performed using one-way analysis of variance (ANOVA), followed by Bonferroni's post hoc test. When appropriate, the results were analyzed using unpaired 
Student's $t$ test. MET and open-field parameters were analyzed using paired Student's $t$ tests. Systolic blood pressure before and $48 \mathrm{~h}$ after surgery were analyzed using Student's $t$ tests. Differences with $p$ values less than 0.05 were considered significant. All calculations were performed using commercially available statistical software (GraphPad Prism Software, CA, USA).

\section{Results}

Early moderate physical exercise reduced systolic blood pressure in animals with chronic cerebral hypoperfusion The SBP of all animal groups was assessed before 2VO or sham surgery, $48 \mathrm{~h}$ after $2 \mathrm{VO}$ or sham surgery and at the end of 12 weeks of physical exercise (2VO-Ex and Sham-Ex) or physical inactivity (2VO-Sed and ShamSed). At baseline, all animals exhibited similar SBP (data not shown). As expected, $48 \mathrm{~h}$ after $2 \mathrm{VO}$ surgery an increase in SBP was observed, compared to those submitted to sham surgery (Table 1 ). At 12 weeks the SBP was higher in the 2VO-Sed group compared to the respective sham groups. Moreover, physical exercise was able to bring SBP back to basal levels in the 2VO-Ex group.

\section{Physical performance was not altered in animals with chronic cerebral hypoperfusion}

Prior to the physical exercise protocol, animals were adapted to the treadmill for 3 days before the surgical procedure, and then submitted to the MET for the correct prescription of exercise intensity for the course of this investigation. Table 2 shows that both exercised groups presented improvement at the readjustment MET when compared with pre-training values, regarding time to exhaustion, maximal speed, maximal distance and training velocity. No differences were found between

Table 1 Systolic blood pressure (SBP) during chronic cerebral hypoperfusion

\begin{tabular}{lll}
\hline & Groups & SBP \\
\hline 48 h after surgery & Sham & $130.4 \pm 2.24$ \\
& 2 VO & $147 \pm 4.30^{\S \S}$ \\
after 12 weeks with or without & Sham-Sed & $131 \pm 2.3$ \\
physical exercise & Sham-Ex & $125 \pm 4.44$ \\
& 2VO-Sed & $140.7 \pm 1.75^{*}$ \\
& 2VO-Ex & $130 \pm 2.06 \#$
\end{tabular}

Systolic blood pressure (SBP) during chronic cerebral hypoperfusion. Results are expressed as the mean \pm SEM of 9 animals per group. SBP at $48 \mathrm{~h}$ after sham or 2VO surgery. Systolic blood pressure before and $48 \mathrm{~h}$ after surgery were analyzed using Student's $t$ tests and after 12 weeks with or without physical exercise was analyzed using ANOVA. Sham sham surgery group, 2VO chronic cerebral hypoperfusion, Sham-Sed sham surgery non-exercised group, Sham-Ex sham surgery exercised group, 2VO-Sed chronic cerebral hypoperfusion non-exercised group, 2VO-Ex chronic cerebral hypoperfusion exercised group

${ }^{\S \S} p<0.01$ vs. Sham

\# $p<0.05$ vs. 2 VO-Sed

$\# p<0.01$ vs. 2 VO-Sed
Table 2 Physical performance in the maximal exercise test

\begin{tabular}{|c|c|c|}
\hline Parameter & Sham-Ex & 2VO-Ex \\
\hline \multicolumn{3}{|l|}{ Time to exhaustion (min) } \\
\hline Baseline & $14.52 \pm 1.74$ & $14.63 \pm 2.14$ \\
\hline Readjustment & $20.89 \pm 1.21 * *$ & $19.57 \pm 1.89^{\S}$ \\
\hline \multicolumn{3}{|l|}{ Maximal speed (m/min) } \\
\hline Baseline & $25.00 \pm 0.91$ & $25.75 \pm 0.84$ \\
\hline Readjustment & $29.10 \pm 1.23 *$ & $30.00 \pm 0.77^{\S}$ \\
\hline \multicolumn{3}{|l|}{ Maximal distance (m) } \\
\hline Baseline & $283.00 \pm 23.38$ & $322.00 \pm 23.64$ \\
\hline Readjustment & $405.00 \pm 31.64^{*}$ & $429.70 \pm 23.03^{\S \S}$ \\
\hline \multicolumn{3}{|l|}{ Training velocity (m/min) } \\
\hline Baseline & $15.00 \pm 0.54$ & $15.45 \pm 0.50$ \\
\hline Readjustment & $17.45 \pm 0.74 *$ & $18.00 \pm 0.46^{\S \S}$ \\
\hline \multicolumn{3}{|c|}{$\begin{array}{l}\text { MET was performed } 3 \text { days after } 2 \mathrm{VO} \text { or sham surgery and on the sixth week } \\
\text { of exercise to determine the appropriate exercise training for the duration of } \\
\text { the investigation. Sham-Ex, sham surgery exercised group }(n=12) ; 2 \mathrm{VO}-\mathrm{Ex} \text {, } \\
\text { chronic cerebral hypoperfusion exercised group }(n=15) \text {. Values represent the } \\
\text { mean } \pm \text { SEM } \\
{ }^{*} p<0.05 \text { vs. Sham-Ex baseline } \\
*^{* *} p<0.01 \text { vs. Sham-Ex baseline } \\
{ }^{\$} p<0.05 \text { vs. } 2 \text { VO-Ex baseline } \\
{ }^{\$ \S} p<0.01 \text { vs. } 2 \text { VO-Ex baseline (Student's } t \text { test) }\end{array}$} \\
\hline
\end{tabular}

the groups that received either the $2 \mathrm{VO}$ or sham surgery.

\section{Early moderate physical exercise was able to improve memory habituation in animals with chronic cerebral hypoperfusion}

After 12 weeks of physical exercise or sedentarism, animals were evaluated for cognitive function by the open-field test. This test is based on the tendency of rodents to explore a new environment more than a familiar one. During a training day, animals are allowed to explore and familiarize themselves with an open-field arena, which has a grid marked. The following test day, the animals are expected to recognize and explore the environment less. For the Sham-Sed and Sham-Ex groups, there were a reduced number of gridline crossings and hind leg rearings in the test day suggesting familiarity with the environment (Fig. 1a, b). Whereas the 2VO-Sed animals showed no difference in the exploratory profile on training and test days. This trend was absent in the 2VO-Ex animals which demonstrated a reduction in environmental exploration on the test day indicating intact cognitive skills.

\section{Early moderate physical exercise was able to normalize functional capillary density and reduce leukocyte rolling in the brain of animals with chronic cerebral hypoperfusion}

We next analyzed brain microcirculation and inflammatory cell dynamics by intravital microscopy. A reduced number of perfused capillaries was observed in the 


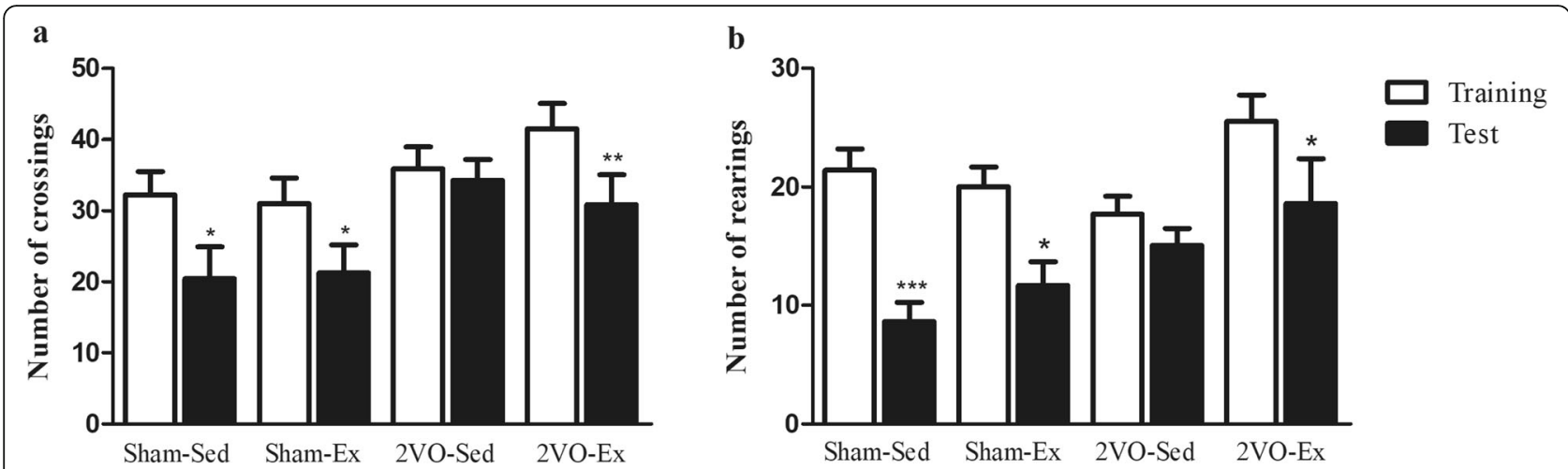

Fig. 1 Analysis of cognitive function by open-field test. Bars represent the mean \pm S.E.M. ( $n=12-15$ animals per group). a The number of gridline crossings, and $\mathbf{b}$ the number of hind leg rearing of the animals on the training day (white bars) and $24 \mathrm{~h}$ later on the test day (black bars). Sham-Sed, sham surgery non-exercised group; Sham-Ex, sham surgery exercised group; 2VO-Sed, chronic cerebral hypoperfusion non-exercised group; 2VO-Ex, chronic cerebral hypoperfusion exercised group. ${ }^{*} p<0.05,{ }^{* *} p<0.01$, and ${ }^{* * *} p<0.001$ vs. training day (paired Student's $t$ test)

cortical area of the brains of the 2VO-Sed group when compared to Sham-Sed group (Fig. 2a). The reduction in the number of perfused capillaries was prevented in the 2VO-Ex group, as capillary density in the 2VO-Ex was not significantly different from the sham groups.

We also evaluated the rolling of leukocytes on postcapillary venules. Changes in leukocyte-endothelial interactions were observed in the 2VO-Sed animals, which exhibited increased leukocyte rolling in brain vessels when compared to the Sham-Sed group, while physical exercise prevented this inflammatory event in the 2VOEx group (Fig. 2b).

\section{Early moderate physical exercise restored synaptic proteins expression in the brain of animals with chronic cerebral hypoperfusion}

In order to investigate the effects of chronic hypoperfusion on the expression of hippocampal plasticity-related proteins, we performed western blots for the detection of synaptophysin and PSD-95 in the hippocampus of animals. Early physical exercise was able to increase synaptophysin expression in the brain of both exercised groups (Fig. 3a). Similarly, increased expression of PSD95 was detected in the 2VO-Ex group with statistical significance of $p=0.556$ (Fig. 3b).

\section{Early moderate physical exercise improves astrocytes coverage in blood vessels of the cerebral cortex and hippocampus of animals with chronic cerebral hypoperfusion}

We also investigated the interaction of astrocytes with the vasculature in the cortex and hippocampus (Fig. 4a). Immunohistochemical analysis allowed the evaluation of vessel coverage by astrocytes on the cerebral microcirculation, which is an important feature of the neurovascular unit and BBB integrity. Animals that were submitted to chronic cerebral hypoperfusion but not to physical exercise presented a significant reduction in the amount of $\mathrm{IB}^{+}{ }^{+}$vessels surrounded by $\mathrm{GFAP}^{+}$astrocytes in the cortex and hippocampus (Fig. 4). Physical exercise recovered astrocytes vessel coverage in both the cortex and hippocampus in the $2 \mathrm{VO}$ animals (Fig. 4a, b). Although there were no differences between the Sham-Sed and Sham-Ex groups compared to the 2VO-Ex in the hippocampus, there was a reduction in the Sham-Sed group in the cerebral cortex.

Physical exercise decreases microglial activation in the hippocampus from animals submitted to chronic cerebral hypoperfusion

We next investigated the effects of physical exercise on microglial morphology following the $2 \mathrm{VO}$ protocol. Although isolectin IB4 stains both microglia and vessels, labeling with the microglia-specific IBA1 enabled the morphology of these cells to be observed more clearly. Analysis of parenchymal $\mathrm{Iba}^{+}$cells in the 2VO-Ex group revealed an increase in the number of microglia compared to respective sedentary group (Fig. 5a). In the 2VO-Sed group, microglia displayed an amoeboid phenotype and increased soma when compared to Sham-Sed group, whilst both the 2VO-Ex and the Sham-Ex groups presented microglia with more ramified morphology (Fig. 5b). This was supported by quantitative data obtained by Sholl analysis showing that the maximum number of microglia process interactions and the distance from the soma where these interactions occurred was significantly decreased in the 2VO-Sed group, but not in the exercised groups, that had levels similar to sham animals (Fig. 5c).

\section{Early moderate physical exercise improves structural capillaries in hippocampus}

Further investigation of the structural capillaries in the cortex and hippocampus was performed by the AngioTool 

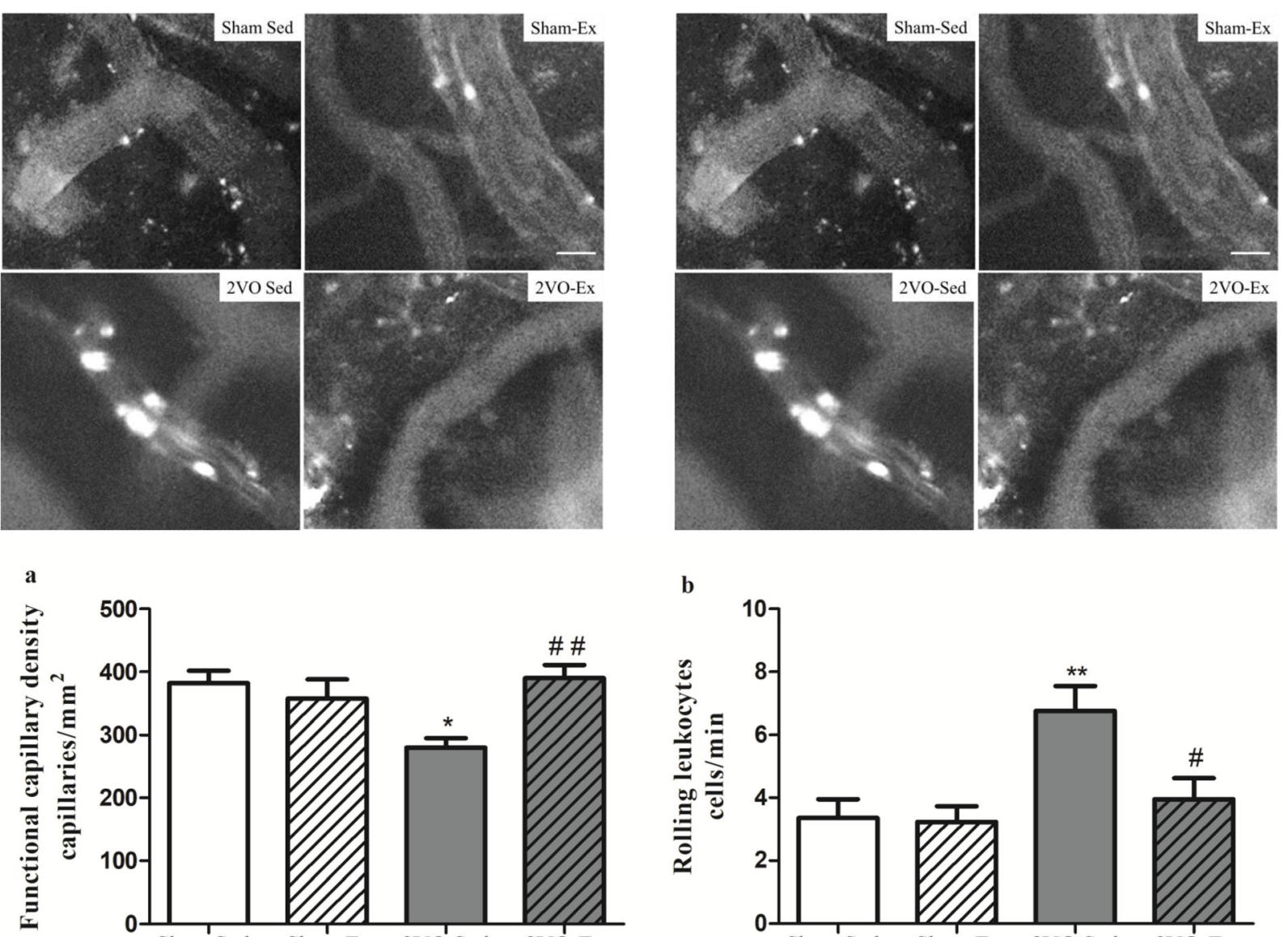


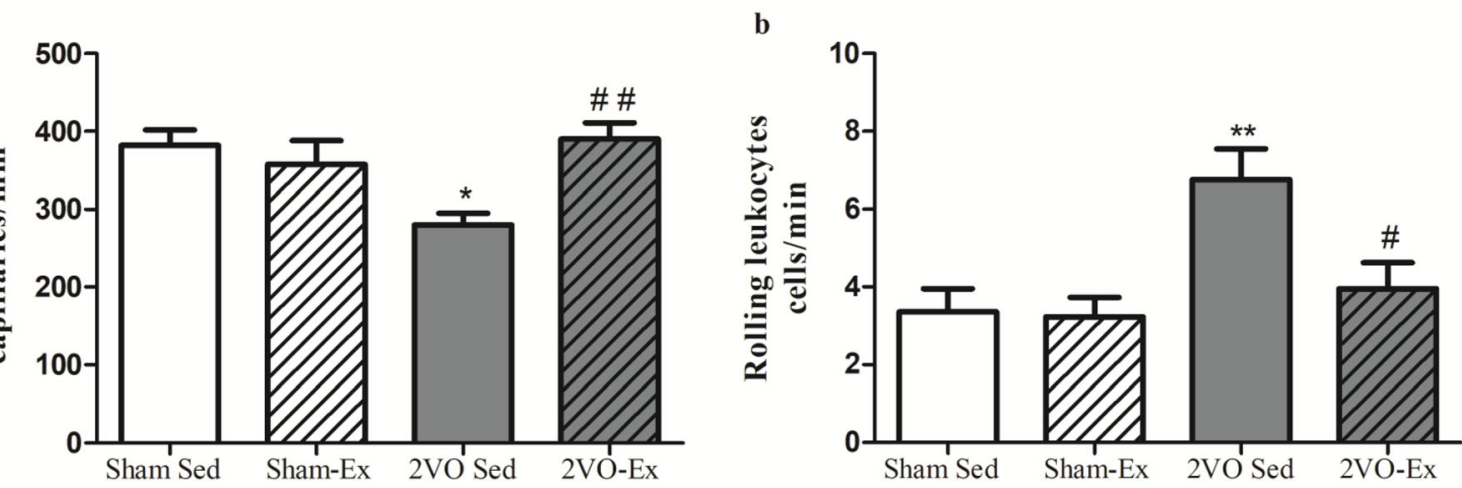

Fig. 2 Representative images of cerebral intravital microscopy and microcirculation analysis of the cerebral cortex. The values represent the mean \pm S.E.M ( $n=6-8$ per group). Bar graphs represent $\mathbf{a}$ the functional capillary density, and $\mathbf{b}$ the number of rolling leukocytes in venules after 12 weeks of physical exercise or sedentarism. Sham-Sed, sham surgery non-exercised group; Sham-Ex, sham surgery exercised group; 2VO-Sed, chronic cerebral hypoperfusion non-exercised group; 2VO-Ex, chronic cerebral hypoperfusion exercised group. In a ${ }^{*} p<0.05$ vs. Sham-Sed and

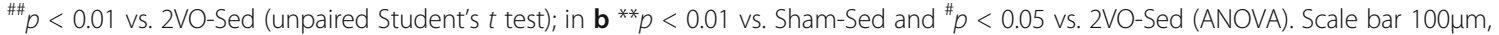
magnification 100X in a and 200X in b

technique. There were no significant differences in the length of the capillaries of the cortex (Fig. 6a). However, exercise was able to increase capillary length in the hippocampus in the 2VO-Ex group compared to the sedentary 2VO-Sed group (Fig. 6b).

\section{Discussion}

Using a two-vessel occlusion model, $2 \mathrm{VO}$, in rats we found that chronic cerebral hypoperfusion (i) caused a reduction in habituation memory; (ii) induced brain functional capillary rarefaction, as well as an increase in rolling leukocytes to the microvascular endothelium; (iii) induced alterations in astrocyte coverage of brain microvessel; and (iv) induced microglia activation phenotype. In addition, early intervention with moderate physical exercise over a period of 12 weeks effectively reduced systolic blood pressure and vascular inflammation in the post-capillary venules; increased the total length of capillaries in the hippocampus; improved coverage of astrocytes on cerebral capillaries; improved microglia activation phenotype; and improved habituation memory accompanied by an increase in the expression of synaptophysin and PSD-95 proteins.

Following the 2VO surgery, the systolic blood pressure was increased, which likely occurred due to a reduction in carotid blood flow after occlusion. This in turn reduces the stretching of the arterial walls resulting in reduced baroreceptor stimulation, which responds to the fall in blood pressure by increasing sympathetic tone, consequently increasing the systemic blood pressure [4]. Previous studies that analyzed the mean blood pressure found significant increases after $2 \mathrm{VO}$ in both the shortterm [14, 33] and the long-term [34]. This was reported by Farkas and colleagues who described a 10 to 20 $\mathrm{mmHg}$ increase in systolic blood pressure at $24 \mathrm{~h}$ after 2VO, persisting for up to 9 weeks [4]. Physical training, 

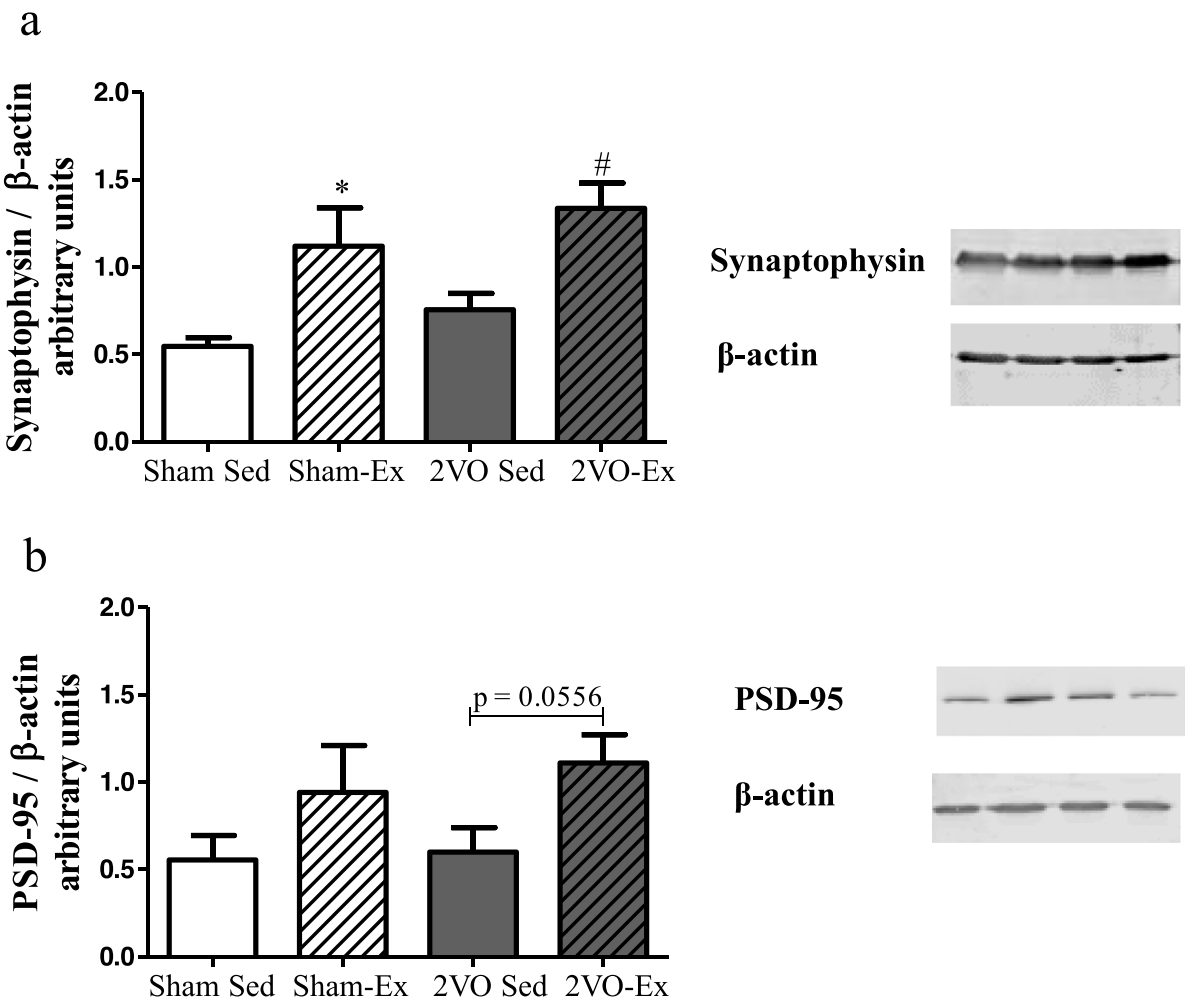

Fig. 3 Western blot analysis for the expression of synaptophysin (a) and PSD-95 (b) in the hippocampus. Values represent the mean \pm S.E.M. of 4-7 animals per group. Quantitative protein expression of synaptophysin and PSD-95 bands detected by Western blot using $\beta$-actin as a loading control (c). Sham-Sed, sham surgery non-exercised group; Sham-Ex, sham surgery exercised group; 2VO-Sed, chronic cerebral hypoperfusion nonexercised group; 2VO-Ex, chronic cerebral hypoperfusion exercised group. In $\mathbf{a}^{*} p<0.05$ vs. Sham-Sed and ${ }^{\#} p<0.05$ vs. 2 VO-Sed (unpaired Student's $t$ test); in $\mathbf{b} \# p=0.0556$ vs. 2VO-Sed (unpaired Student's $t$ test).

particularly aerobic exercise, has been shown to be an effective non-pharmacological therapeutic approach in the reduction of blood pressure in models of metabolic syndrome [35] and hypertension [36]. A normalization in systolic blood pressure was observed in our $2 \mathrm{VO}$ model after 12 weeks of moderate exercise compared to animals that were sedentary for this period. Endothelial dysfunction is considered one of the central mechanisms of structural and functional vascular changes in neurodegenerative diseases. In the 2VO model, it has been observed that endothelial activation markers increase 1 day post-occlusion to 28 days, with a peak at 3 days [37]. Yata et al. found increased leukocyte rolling and adhesion in pial surface venules after $24 \mathrm{~h}, 1$, and 2 weeks of cerebral hypoperfusion suggesting that leukocyte activation may be the first step in the whole neurovascular unit stress response to chronic cerebral hypoperfusion [38]. Previous results from our group have shown that physical exercise initiated early following $2 \mathrm{VO}$ and maintained for 1 week was able to reduce adherent leukocytes in brain venules and to reduce NADPH-oxidase expression in the brain [14]. Here, we observed that 12 weeks of physical exercise was able to reduce the rolling of leukocytes on brain venules.
Further positive effects of physical exercise following $2 \mathrm{VO}$ were observed, such as the ability to normalize the functional capillary density in the cerebral cortex and an increase in the total length capillaries in the hippocampus. Our observations are in agreement with previous studies showing that physical training can induce an increase in cortical capillary density and lead to the growth of new capillaries in the brain, especially in the motor cortex [39-41]. Although we have not quantified the influence of angiogenic factors on the response of physical exercise to cerebral microcirculation, several studies suggest the participation of VEGF as an important factor in increasing the structural capillary density in central and peripheral vascular beds after physical exercise [42, 43]. Physical exercise for 4 months in aged rats was able to increase the volume, capillary length, and total surface area of capillaries in the cerebral cortex [44]. De Jong et al. observed that the cognitive performance of rats submitted to $2 \mathrm{VO}$ correlated closely with capillary morphology in the hippocampal CA1 area, suggesting that capillary integrity is one of the important determinants of brain function [45]. Furthermore, a positive correlation between cognition and brain nutrition has been demonstrated in several studies $[45,46]$. 


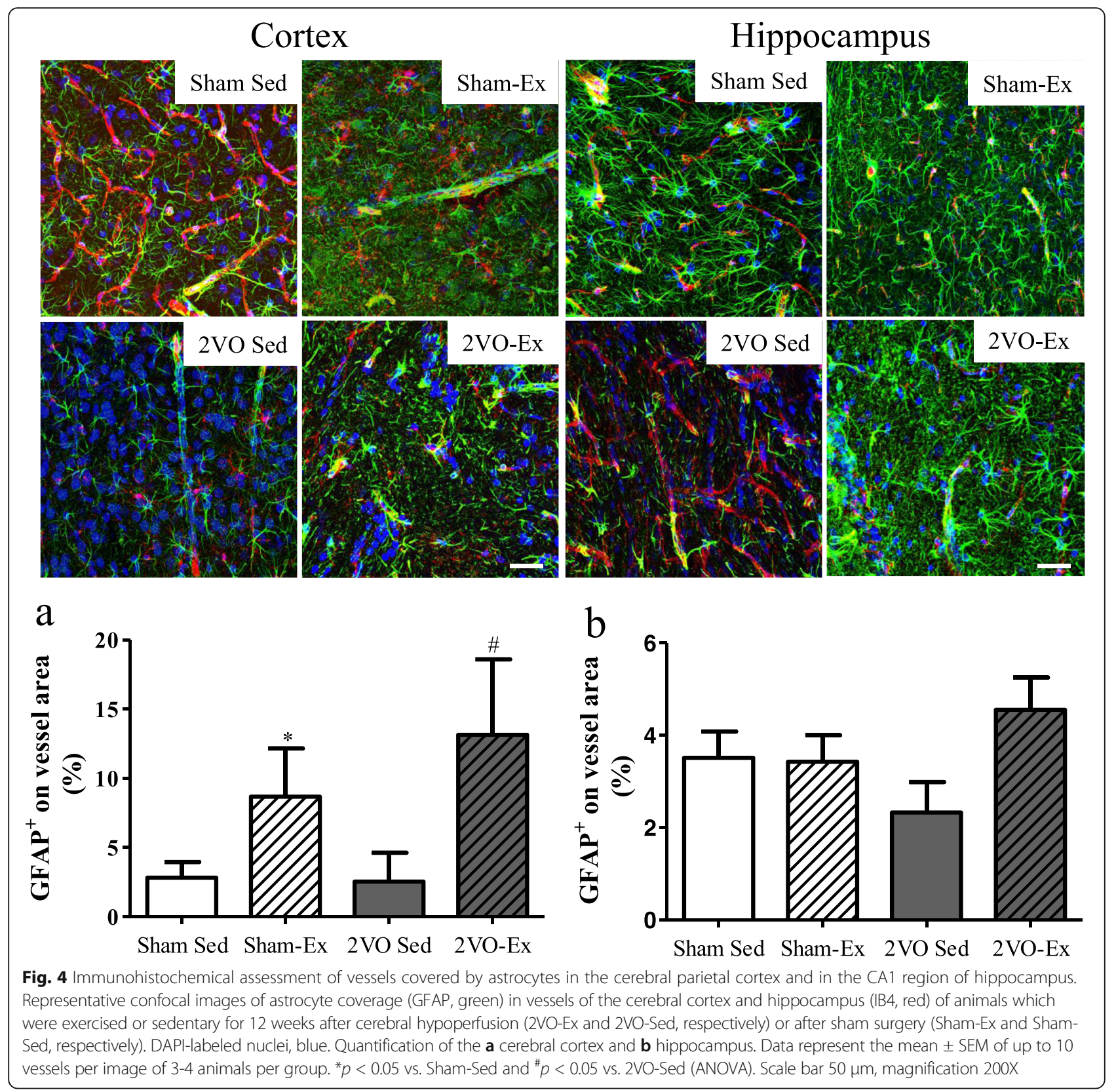

Our results showed that when animals are sedentary following chronic cerebral hypoperfusion their exploratory response was unchanged when presented a second time to a same environment, suggesting they did not consolidate memory. Cognitive dysfunction analyzed by other tests, such as the Morris water maze or radial arm maze tasks, has been widely reported in this model during the chronic phase $[47,48]$. However, upon physical exercise the animals explored the environment less in the test session when compared to the training session, suggesting familiarity with the environment and thus normal cognitive function. A study by Choi et al. corroborates these findings by showing that aerobic exercise, started 3 weeks after $2 \mathrm{VO}$ and maintained for 4 weeks, was able to reduce cognitive impairment and increase hippocampal neurogenesis in a murine model of dementia [49]. Cechetti et al. also demonstrated that forced treadmill exercise prevents oxidative stress and memory deficits following chronic cerebral hypoperfusion [50].

Although the exact molecular mechanisms by which physical training affects brain function are unclear, it is suggested that inhibition of cellular and molecular pathways involved in neuroinflammation contributes to neuroprotection. Positive regulation of the expression of neurotrophic factors, such as synaptophysin, a presynaptic marker, and PSD-95, a postsynaptic marker may help 


\section{Hippocampus}
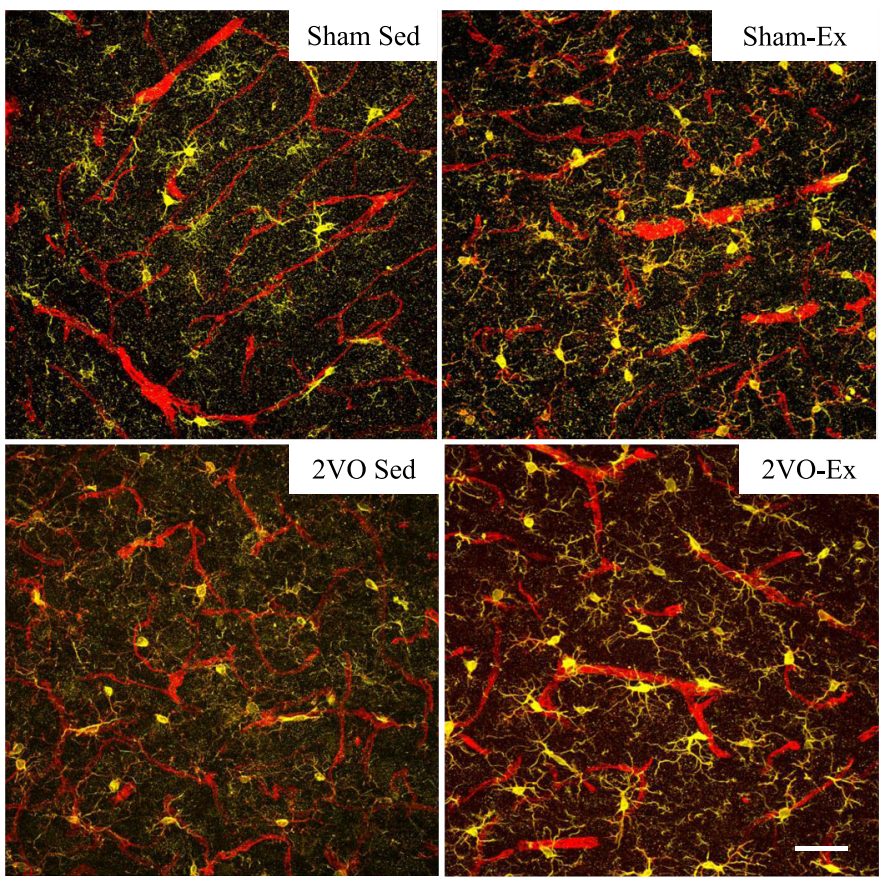

a

b
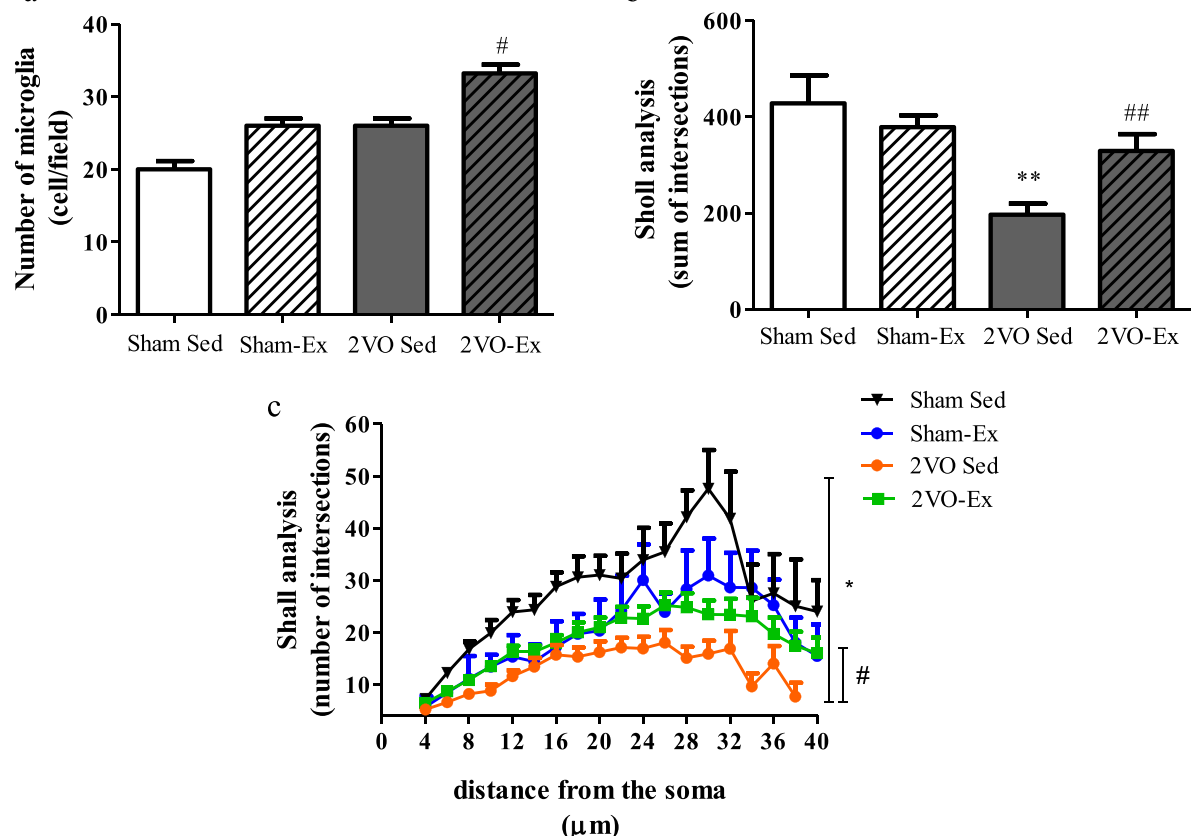

Fig. 5 Exercise increases the number of microglia process in the CA1 region of hippocampus following cerebral hypoperfusion. Representative confocal images of microglia morphology (Iba1 ${ }^{+}$, yellow) in vessels of the hippocampus (IB4, red) of animals that were exercised or sedentary for 12 weeks after cerebral hypoperfusion (2VO-Ex and 2VO-Sed, respectively) or after sham surgery (Sham-Ex and Sham-Sed, respectively). Data represent the mean \pm SEM of up to 40 microglial cells per group of 3 animals. In a number of microglia in the hippocampus, $\mathbf{b}$ and $\mathbf{c}$ number of microglia branches. ${ }^{*} p<0.05$ vs. Sham-Sed and ${ }^{* *} p<0.01$ vs. Sham-Sed; $p<0.05$ and ${ }^{\# \#} p<0.01$ vs. 2VO-Sed (ANOVA). Scale bar $50 \mu$ m, magnification $200 X$

in understanding the protective effects induced by physical exercise. We analyzed expression of these proteins in the hippocampus, which is the memory storage center and an important region for the habituation memory to a new environment. We observed that moderate physical exercise for 12 weeks was able to increase protein content of synaptophysin and PSD-95 in animals submitted to $2 \mathrm{VO}$ model. Although not significant, the decrease in 

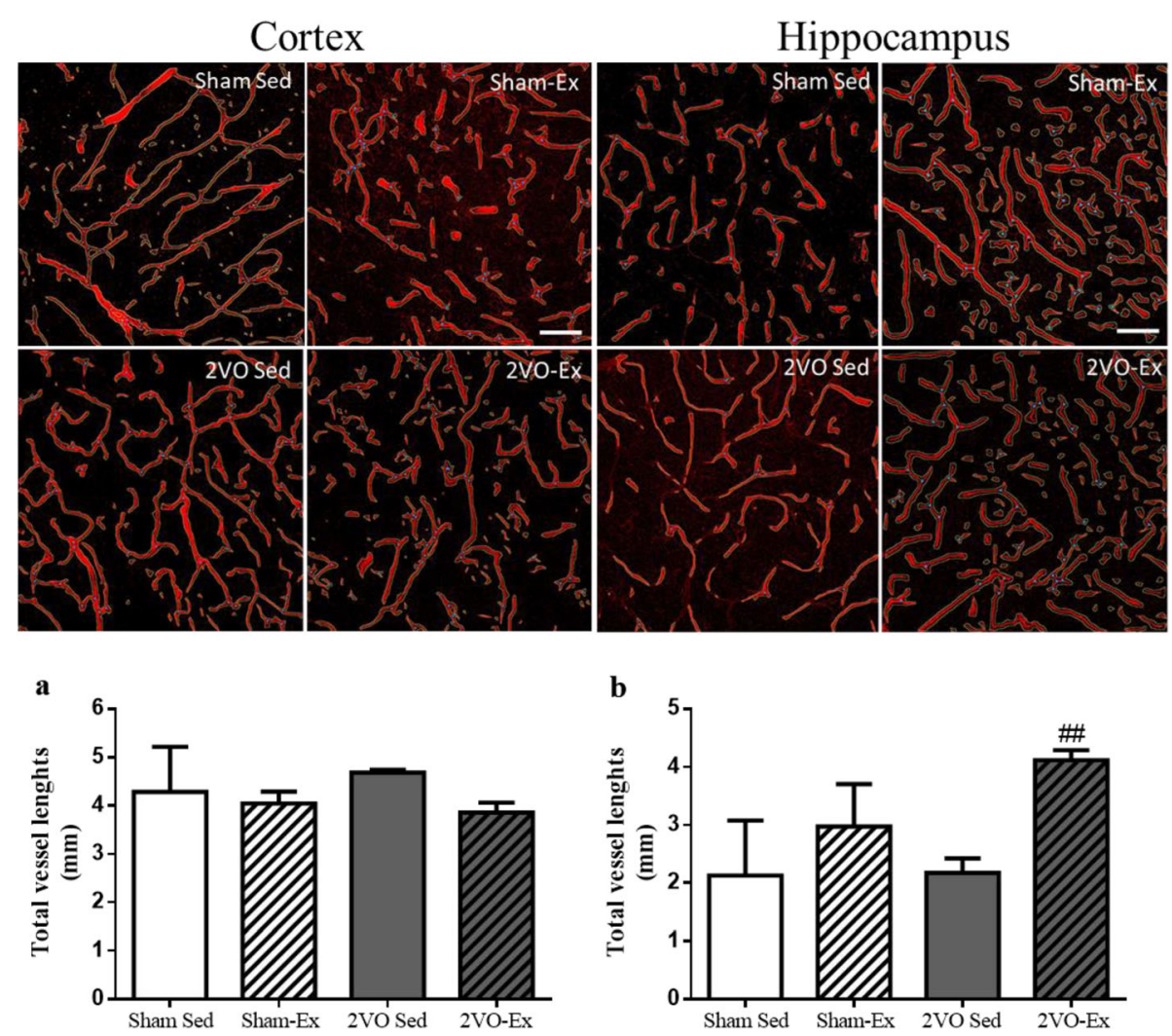

Fig. 6 Structural brain capillaries assessed by AngioTool analysis. Data represent the mean \pm SEM of 4 images per group of 3 animals. Total length of the vessels in $\mathbf{a}$ the cortex and $\mathbf{b}$ the hippocampus of rats submitted to $2 \mathrm{VO}$ and sedentary (2VO-Sed) or exercised (2VO-Ex) for 12 weeks, and their respective controls that had been submitted to sham surgery (Sham-Sed and Sham-Ex). ${ }^{\# \#} p<0.01$ vs. 2VO-Sed (ANOVA).Scale bar $50 \mu m$, magnification $200 X$

blood pressure observed in the Sham-Ex group may be related to the increase in synaptic proteins synaptophysin, therefore, it can contribute to the improvement of neuronal plasticity, even in the absence of cerebral hypoperfusion. Corroborating our results, other experimental studies have also shown that aerobic exercise was able to increase synaptophysin and PSD-95 levels in the hippocampus and prefrontal cortex of healthy, ischemic, and obese rats [51-53].

Microvascular inflammation and endothelial activation markers are associated with progressive changes in neurovascular unit. It is still unknown whether inflammation is the main cause of the cognitive impact in cerebrovascular diseases and whether this is triggered by cerebral or systemic processes. However, interruption of the interaction between glia cells and vessels probably contributes to the disruption of homeostasis [54].

Microglia are CNS-resident immune cells that actively participate in neuronal homeostasis and adult neural pathology. Under normal physiological conditions, the microglia monitors the microenvironment and communicates bidirectionally with the neurons [55]. During their native resting state, microglia have small cell bodies with numerous long and highly branching processes, displaying high ramification.
However, during pathological conditions such as infections, trauma, or cerebral ischemia, microglia rapidly change their morphology from branched cells to reactive cells with thickened and retracted processes, acquiring a more rounded shape, referred to as amoeboid $[55,56]$. Chronic microglial activation is an important feature of many neurodegenerative diseases contributing significantly to disease progression [10]. Thus, the modulation of microglial activation has been the subject of intensive research efforts as a potential therapeutic target.

Physical exercise as a therapeutic approach has been shown to significantly attenuate microglia activation in aging [57-59]. The improvement in cognitive function was associated with changes in modulation of the microglial phenotype from proinflammatory $\mathrm{M} 1$ to antiinflammatory M2 in the corpus callosum, after 28 days of exercise in rats with chronic cerebral hypoperfusion [60]. These studies support our data showing that moderate physical training reduced microglial activation and increased the number of its branches in rats with brain chronic hypoperfusion. Branched microglia are constantly "monitoring" the microenvironment in order to respond promptly to a pathological event. Results from 
other groups indicated that exercise for 8 weeks before the $2 \mathrm{VO}$ was able prevent the activation of microglia and astrocytes, accompanied by reduction of neuronal apoptosis [61].

In addition to microglial analysis, we examined the protective effects of moderate physical exercise on vessel coverage by astrocytes in animals with chronic cerebral hypoperfusion. These cells are part of the neurovascular unit and $\mathrm{BBB}$, playing a key role in the structure of the $\mathrm{BBB}$, in the communication with neurons, glutamate homeostasis [62], and also stimulating the release of vasoactive compounds in microcirculation.

Previous experimental work has shown that physical exercise was able to increase the levels of the astrocyte marker, GFAP, in the hippocampus [63] and induce changes in the astrocyte morphology, suggesting beneficial effects on neuronal activity and plasticity [63]. In a recent study, an increase in the number of astrocytic processes during the exercise protocol was observed in other brain areas, such as the prefrontal cortex, striatum, and entorhinal cortex of mice [64].

In the present work, we used immunohistochemistry analysis to evaluate the coverage of astrocytes on brain microvessels. Our results showed that early and longterm physical exercise after cerebral hypoperfusion increased the astrocytic coverage of cerebral blood vessels in parietal cortex and CA1 region of the hippocampus, regions of the brain associated with learning and memory processes. Astrocyte coverage is important for BBB integrity and for the cross-talk between neurons and vessels. This result highlights the important impact of physical exercise on the neurovascular unit.

Until recently, reactive astrogliosis was a reliable and sensitive marker of diseased tissue. However, there is a growing body of evidence that points towards the potential protective contributions of astrocytes during to pathological mechanisms. Astrocytes are considered to provide a suitable environment for neuron function. It is known that the density of GFAP differs between brain regions; however, our results suggest that the differences observed in the distribution of processes of astrocytes are part of the response to ischemic injury induced by $2 \mathrm{VO}$ and improved by physical exercise. Substantial increases in astroglial metabolism and synaptic protein synthesis, consistent with healthy cellular hypertrophy in response to increased physiological demands, indicates the importance of these cells in neuronal plasticity and regulation of cerebral microcirculation $[65,66]$.

Our results are in accordance with this data, as the increase in astrocytic processes found in the brains of the exercised animals was accompanied by a reduction in microglia activation, an increase in the synaptic proteins, synaptophysin and PSD-95, normalization of brain microcirculation and improvement in cognitive function.
Limitations of this study should be considered. It is well known that differences in brain regions, such as cortex and hippocampus, as well as variations in behavior between males and females. Therefore, in this study we used only male rats to avoid any hormonal interference that may occur in the results $[67,68]$. However, most studies are moving away from this paradigm and in our future studies, we will make efforts to perform on heterogeneous samples that comprise male and female animals.

In conclusion, to our knowledge, this is the first study that has examined the effect of physical exercise on a chronic cerebral hypoperfusion model, reporting differences in the astrocytic coverage of cerebral blood vessels associated with microcirculation and cognitive function.

\section{Conclusions}

Cerebral microcirculatory and inflammatory changes important in the neurodegenerative process are triggered in the initial phase of cerebral hypoperfusion and maintained during the chronic phase. We suggest that early and longterm moderate exercise induce significant improvements in brain inflammation and cognition, highlighting the neuroprotective potential of physical exercise on astrocytes coverage on brain microcirculation.

The present findings have important implications for improving care of neurodegenerative diseases. Therefore, further evaluation of physical exercise as a non-pharmacological approach may assist in the discovery of neuroprotective mechanisms. Recommending physical exercise could prevent or reduce cognitive changes and their evolution to dementia, thus improving the quality of life of these patients.

\section{Abbreviations}

BBB: Blood-brain barrier; BSA: Bovine serum albumin; CBF: Cerebral blood flow; 2VO: 2-vessel occlusion; Iba-1: Ionized calcium-binding adaptor-1; GFAP: Glial fibrillary acidic protein; MET: Maximal exercise testing; SBP: Systolic blood pressure; PSD-95: Postsynaptic density protein 95

\section{Acknowledgements}

We would like to thank the Confocal Platform from Oswald Cruz Foundation and the Confocal Microscopy Unit from the Graduate Program in

Morphological Sciences at the Federal University of Rio de Janeiro for their support with the immunohistochemistry images.

\section{Authors' contributions}

$M L-T, V E$, and ET conceived the study and design; ML-T and GA conducted the experiments; CG and FL executed immunohistochemistry experiments; VE analyzed immunofluorescence; ML-T and EM conducted cognitive tests; $M L-T$ and PR supervised cognitive tests; ML-T, ML, and GA performed western blotting; ML-T and PR supervised western blotting; ML-T, VE, ET, and HN assisted with funding, experimental design, analyzed the data, and edited the manuscript. All authors read, revised, and approved the final manuscript.

\section{Funding}

This work was sponsored by Conselho Nacional de Desenvolvimento Científico e Tecnológico- CNPq and Fundação de Amparo à Pesquisa do Estado do Rio de Janeiro- FAPERJ. 


\section{Availability of data and materials}

The datasets used and/or analyzed during the current study are available from the corresponding author on reasonable request.

\section{Ethics approval and consent to participate}

All experiments were conducted in accordance with internationally accepted principles for the care and use of laboratory animals and were approved by the Animal Ethics Committee of the Oswaldo Cruz Foundation (protocol number L-002/2016).

\section{Consent for publication}

Not applicable

\section{Competing interests}

The authors declare no competing interests

\section{Author details}

'Laboratory of Immunopharmacology, Oswaldo Cruz Foundation, Av. Brasil, 4365, Manguinhos, Rio de Janeiro 21040-900, Brazil. '2Laboratory of Cardiovascular Investigation, Oswaldo Cruz Foundation, Rio de Janeiro, Brazil. ${ }^{3}$ Laboratory of Glial Cell Biology, Biomedical Sciences Institute, Federal University of Rio de Janeiro, Rio de Janeiro, Brazil. ${ }^{4}$ National Institute of Cardiology, Rio de Janeiro, Brazil.

Received: 6 January 2020 Accepted: 12 March 2020

Published online: 16 April 2020

\section{References}

1. Sacuiu SF. Dementias. Handb Clin Neurol. 2016;138:123-51.

2. Pantoni L. Cerebral small vessel disease: from pathogenesis and clinical characteristics to therapeutic challenges. Lancet Neurol. 2010;9:689-701.

3. Schmidt-Kastner R, Aguirre-Chen C, Saul I, Yick L, Hamasaki D, Busto R, Ginsberg MD. Astrocytes react to oligemia in the forebrain induced by chronic bilateral common carotid artery occlusion in rats. Brain Res. 2005; 1052:28-39

4. Farkas E, Luiten PG, Bari F. Permanent, bilateral common carotid artery occlusion in the rat: a model for chronic cerebral hypoperfusion-related neurodegenerative diseases. Brain Res Rev. 2007;54:162-80.

5. Kelly P, Denver P, Satchell SC, Ackermann M, Konerding MA, Mitchell CA Microvascular ultrastructural changes precede cognitive impairment in the murine APPswe/PS1dE9 model of Alzheimer's disease. Angiogenesis. 2017; 20:567-80

6. Gorelick PB, Scuteri A, Black SE, Decarli C, Greenberg SM, ladecola C, Launer L, Laurent S, Lopez OL, Nyenhuis D, et al. Vascular contributions to cognitive impairment and dementia: a statement for healthcare professionals from the american heart association/american stroke association. Stroke. 2011:42:2672-713.

7. Preston AR, Eichenbaum H. Interplay of hippocampus and prefrontal cortex in memory. Curr Biol. 2013;23:R764-73.

8. Huang L, Nakamura Y, Lo EH, Hayakawa K. Astrocyte Signaling in the Neurovascular Unit After Central Nervous System Injury. Int J Mol Sci. 2019; 20(2):282.

9. Lucin KM, Wyss-Coray T. Immune activation in brain aging and neurodegeneration: too much or too little? Neuron. 2009;64:110-22.

10. Ma Y, Wang J, Wang Y, Yang GY. The biphasic function of microglia in ischemic stroke. Prog Neurobiol. 2017;157:247-72.

11. Kim JY, Park J, Chang JY, Kim SH, Lee JE. Inflammation after Ischemic Stroke: The Role of Leukocytes and Glial Cells. Exp Neurobiol. 2016;25:241-51.

12. Liu N, Cadilhac DA, Andrew NE, Zeng L, Li Z, Li J, Li Y, Yu X, Mi B, Li Z, et al. Randomized controlled trial of early rehabilitation after intracerebral hemorrhage stroke: difference in outcomes within 6 months of stroke. Stroke. 2014;45:3502-7.

13. Sundseth A, Thommessen B, Ronning OM. Outcome after mobilization within 24 hours of acute stroke: a randomized controlled trial. Stroke. 2012; 43:2389-94.

14. Leardini-Tristao M, Borges JP, Freitas F, Rangel R, Daliry A, Tibirica E, Estato V. The impact of early aerobic exercise on brain microvascular alterations induced by cerebral hypoperfusion. Brain Res. 1657;2017:43-51.

15. Miyanohara J, Kakae M, Nagayasu K, Nakagawa T, Mori Y, Arai K, Shirakawa $\mathrm{H}$, Kaneko S. TRPM2 channel aggravates CNS inflammation and cognitive impairment via activation of microglia in chronic cerebral hypoperfusion. J Neurosci. 2018;38:3520-33.

16. van Praag H, Kempermann G, Gage FH. Running increases cell proliferation and neurogenesis in the adult mouse dentate gyrus. Nat Neurosci. 1999;2: 266-70.

17. van Praag H, Shubert T, Zhao C, Gage FH. Exercise enhances learning and hippocampal neurogenesis in aged mice. J Neurosci. 2005;25:8680-5.

18. Mee-Inta O, Zhao ZW, Kuo YM. Physical exercise inhibits inflammation and microglial activation. Cells. 2019;8(7).

19. Camiletti-Moiron D, Aparicio VA, Aranda P, Radak Z. Does exercise reduce brain oxidative stress? A systematic review. Scand J Med Sci Sports. 2013;23:e202-12.

20. Moon HY, Becke A, Berron D, Becker B, Sah N, Benoni G, Janke E, Lubejko ST, Greig NH, Mattison JA, et al. Running-induced systemic cathepsin B secretion is associated with memory function. Cell Metab. 2016;24:332-40.

21. Lourenco MV, Frozza RL, de Freitas GB, Zhang H, Kincheski GC, Ribeiro FC, Goncalves RA, Clarke JR, Beckman D, Staniszewski A, et al. Exercise-linked FNDC5/irisin rescues synaptic plasticity and memory defects in Alzheimer's models. Nat Med. 2019;25:165-75

22. Erickson Kl, Prakash RS, Voss MW, Chaddock L, Hu L, Morris KS, White SM, Wojcicki TR, McAuley E, Kramer AF. Aerobic fitness is associated with hippocampal volume in elderly humans. Hippocampus. 2009:19:1030-9.

23. Colcombe SJ, Kramer AF, Erickson KI, Scalf P, McAuley E, Cohen NJ, Webb A, Jerome GJ, Marquez DX, Elavsky S. Cardiovascular fitness, cortical plasticity, and aging. Proc Natl Acad Sci U S A. 2004;101:3316-21.

24. Voss MW, Erickson Kl, Prakash RS, Chaddock L, Kim JS, Alves H, Szabo A, Phillips SM, Wojcicki TR, Mailey EL, et al. Neurobiological markers of exercise-related brain plasticity in older adults. s. 2013;28:90-9.

25. Farkas E, Donka G, de Vos RA, Mihaly A, Bari F, Luiten PG. Experimental cerebral hypoperfusion induces white matter injury and microglial activation in the rat brain. Acta Neuropathol. 2004;108:57-64.

26. Rodrigues B, Figueroa DM, Mostarda CT, Heeren MV, Irigoyen MC, De Angelis K. Maximal exercise test is a useful method for physical capacity and oxygen consumption determination in streptozotocin-diabetic rats. Cardiovasc Diabetol. 2007:6:38

27. Vianna MR, Alonso M, Viola H, Quevedo J, de Paris F, Furman M, de Stein $\mathrm{ML}$, Medina JH, Izquierdo I. Role of hippocampal signaling pathways in long-term memory formation of a nonassociative learning task in the rat. Learn Mem. 2000;7:333-40.

28. Carvalho-Tavares J, Hickey MJ, Hutchison J, Michaud J, Sutcliffe IT, Kubes P. A role for platelets and endothelial selectins in tumor necrosis factor-alphainduced leukocyte recruitment in the brain microvasculature. Circ Res. 2000; 87:1141-8.

29. Estato V, Obadia N, Carvalho-Tavares J, Freitas FS, Reis P, Castro-Faria Neto $\mathrm{H}$, Lessa MA, Tibirica E. Blockade of the renin-angiotensin system improves cerebral microcirculatory perfusion in diabetic hypertensive rats. Microvasc Res. 2013;87:41-9.

30. Zudaire E, Gambardella L, Kurcz C, Vermeren S. A computational tool for quantitative analysis of vascular networks. PLoS One. 2011;6:e27385.

31. Diniz LP, Matias I, Siqueira M, Stipursky J, Gomes FCA. Astrocytes and the TGF-beta1 pathway in the healthy and diseased brain: a double-edged sword. Mol Neurobiol. 2019:56:4653-79.

32. Giannakaki-Zimmermann H, Kokona D, Wolf S, Ebneter A, Zinkernagel MS. Optical coherence tomography angiography in mice: comparison with confocal scanning laser microscopy and fluorescein angiography. Transl Vis Sci Technol. 2016:5:11.

33. Yilmaz G, Granger DN. Cell adhesion molecules and ischemic stroke. Neurol Res. 2008:30:783-93.

34. Otori T, Katsumata T, Muramatsu H, Kashiwagi F, Katayama Y, Terashi A. Long-term measurement of cerebral blood flow and metabolism in a rat chronic hypoperfusion model. Clin Exp Pharmacol Physiol. 2003;30:266-72.

35. Machado MV, Vieira AB, da Conceicao FG, Nascimento AR, da Nobrega ACL, Tibirica E. Exercise training dose differentially alters muscle and heart capillary density and metabolic functions in an obese rat with metabolic syndrome. Exp Physiol. 2017:102:1716-28.

36. Rossoni LV, Oliveira RA, Caffaro RR, Miana M, Sanz-Rosa D, Koike MK, Do Amara SL, Michelini LC, Lahera V, Cachofeiro V. Cardiac benefits of exercise training in aging spontaneously hypertensive rats. J Hypertens. 2011;29:2349-58.

37. Huang Y, Zhang W, Lin L, Feng J, Chen F, Wei W, Zhao X, Guo W, Li J, Yin W, Li L. Is endothelial dysfunction of cerebral small vessel responsible for white matter lesions after chronic cerebral hypoperfusion in rats? I Neurol Sci. 2010;299:72-80 
38. Yata K, Nishimura Y, Unekawa M, Tomita Y, Suzuki N, Tanaka T, Mizoguchi A, Tomimoto $\mathrm{H}$. In vivo imaging of the mouse neurovascular unit under chronic cerebral hypoperfusion. Stroke. 2014;45:3698-703.

39. Ding YH, Li J, Zhou Y, Rafols JA, Clark JC, Ding Y. Cerebral angiogenesis and expression of angiogenic factors in aging rats after exercise. Curr Neurovasc Res. 2006;3:15-23.

40. Rhyu IJ, Bytheway JA, Kohler SJ, Lange H, Lee KJ, Boklewski J, McCormick K, Williams NI, Stanton GB, Greenough WT, Cameron JL. Effects of aerobic exercise training on cognitive function and cortical vascularity in monkeys. Neuroscience. 2010;167:1239-48.

41. Swain RA, Harris AB, Wiener EC, Dutka MV, Morris HD, Theien BE, Konda S, Engberg K, Lauterbur PC, Greenough WT. Prolonged exercise induces angiogenesis and increases cerebral blood volume in primary motor cortex of the rat. Neuroscience. 2003;117:1037-46.

42. Esposito F, Mathieu-Costello O, Wagner PD, Richardson RS. Acute and chronic exercise in patients with heart failure with reduced ejection fraction: evidence of structural and functional plasticity and intact angiogenic signalling in skeletal muscle. J Physiol. 2018;596:5149-61.

43. Morland C, Andersson KA, Haugen OP, Hadzic A, Kleppa L, Gille A, Rinholm JE, Palibrk V, Diget EH, Kennedy LH, et al. Exercise induces cerebral VEGF and angiogenesis via the lactate receptor HCAR1. Nat Commun. 2017;8:15557.

44. Huang CX, Qiu X, Wang S, Wu H, Xia L, Li C, Gao Y, Zhang L, Xiu Y, Chao F, Tang Y. Exercise-induced changes of the capillaries in the cortex of middleaged rats. Neuroscience. 2013;233:139-45.

45. De Jong Gl, Farkas E, Stienstra CM, Plass JR, Keijser JN, de la Torre JC, Luiten PG. Cerebral hypoperfusion yields capillary damage in the hippocampal CA1 area that correlates with spatial memory impairment. Neuroscience. 1999;91: 203-10.

46. Wightman EL, Haskell-Ramsay CF, Thompson KG, Blackwell JR, Winyard PG, Forster J, Jones AM, Kennedy DO. Dietary nitrate modulates cerebral blood flow parameters and cognitive performance in humans: a double-blind, placebo-controlled, crossover investigation. Physiol Behav. 2015;149:149-58.

47. Sarti C, Pantoni L, Bartolini L, Inzitari D. Cognitive impairment and chronic cerebral hypoperfusion: what can be learned from experimental models. J Neurol Sci. 2002;203-204:263-6.

48. Jiwa NS, Garrard P, Hainsworth AH. Experimental models of vascular dementia and vascular cognitive impairment: a systematic review. J Neurochem. 2010;115:814-28.

49. Choi DH, Lee $\mathrm{KH}$, Lee J. Effect of exercise-induced neurogenesis on cognitive function deficit in a rat model of vascular dementia. Mol Med Rep. 2016;13:2981-90.

50. Cechetti F, Worm PV, Elsner VR, Bertoldi K, Sanches E, Ben J, Siqueira IR, Netto CA. Forced treadmill exercise prevents oxidative stress and memory deficits following chronic cerebral hypoperfusion in the rat. Neurobiol Learn Mem. 2012;97:90-6.

51. Cassilhas RC, Lee KS, Fernandes J, Oliveira MG, Tufik S, Meeusen R, de Mello MT. Spatial memory is improved by aerobic and resistance exercise through divergent molecular mechanisms. Neuroscience. 2012;202:309-17.

52. Lin $Y$, Dong J, Yan T, He X, Zheng $X$, Liang H, Sui M. Involuntary, forced and voluntary exercises are equally capable of inducing hippocampal plasticity and the recovery of cognitive function after stroke. Neurol Res. 2015;37:893-901.

53. Cai M, Wang H, Li JJ, Zhang YL, Xin L, Li F, Lou SJ. The signaling mechanisms of hippocampal endoplasmic reticulum stress affecting neuronal plasticity-related protein levels in high fat diet-induced obese rats and the regulation of aerobic exercise. Brain Behav Immun. 2016;57:347-59.

54. McConnell HL, Kersch CN, Woltjer RL, Neuwelt EA. The Translational Significance of the Neurovascular Unit. J Biol Chem. 2017;292:762-70.

55. Wolf SA, Boddeke HW, Kettenmann H. Microglia in Physiology and Disease. Annu Rev Physiol. 2017;79:619-43.

56. Garcia C, Dubois LG, Xavier AL, Geraldo LH, da Fonseca AC, Correia AH, Meirelles F, Ventura G, Romao L, Canedo NH, et al. The orthotopic xenotransplant of human glioblastoma successfully recapitulates glioblastoma-microenvironment interactions in a non-immunosuppressed mouse model. BMC Cancer. 2014;14:923.

57. He XF, Liu DX, Zhang Q, Liang FY, Dai GY, Zeng JS, Pei Z, Xu GQ, Lan Y. Voluntary exercise promotes glymphatic clearance of amyloid beta and reduces the activation of astrocytes and microglia in aged mice. Front $\mathrm{Mol}$ Neurosci. 2017;10:144.
58. Littlefield AM, Setti SE, Priester C, Kohman RA. Voluntary exercise attenuates LPS-induced reductions in neurogenesis and increases microglia expression of a proneurogenic phenotype in aged mice. J Neuroinflammation. 2015;12:138.

59. Kohman RA, DeYoung EK, Bhattacharya TK, Peterson LN, Rhodes JS. Wheel running attenuates microglia proliferation and increases expression of a proneurogenic phenotype in the hippocampus of aged mice. Brain Behav Immun. 2012;26:803-10.

60. Jiang $T$, Zhang L, Pan X, Zheng H, Chen X, Li L, Luo J, Hu X. Physical exercise improves cognitive function together with microglia phenotype modulation and remyelination in chronic cerebral hypoperfusion. Front Cell Neurosci. 2017:11:404.

61. Lee JM, Kim CJ, Park JM, Song MK, Kim YJ. Effect of treadmill exercise on spatial navigation impairment associated with cerebellar Purkinje cell loss following chronic cerebral hypoperfusion. Mol Med Rep. 2018;17:8121-8.

62. Kubotera $\mathrm{H}$, Ikeshima-Kataoka $\mathrm{H}$, Hatashita $\mathrm{Y}$, Allegra Mascaro AL, Pavone FS, Inoue T. Astrocytic endfeet re-cover blood vessels after removal by laser ablation. Sci Rep. 2019;9:1263.

63. Saur L, Baptista PP, de Senna PN, Paim MF, do Nascimento P, Ilha J, Bagatini PB, Achaval M, Xavier LL. Physical exercise increases GFAP expression and induces morphological changes in hippocampal astrocytes. Brain Struct Funct. 2014;219:293-302.

64. Lundquist AJ, Parizher J, Petzinger GM, Jakowec MW. Exercise induces region-specific remodeling of astrocyte morphology and reactive astrocyte gene expression patterns in male mice. J Neurosci Res. 2019;97:1081-94.

65. McCall MA, Gregg RG, Behringer RR, Brenner M, Delaney CL, Galbreath EJ, Zhang CL, Pearce RA, Chiu SY, Messing A. Targeted deletion in astrocyte intermediate filament (Gfap) alters neuronal physiology. Proc Natl Acad Sci U S A. 1996:93:6361-6.

66. Prebil M, Jensen J, Zorec R, Kreft M. Astrocytes and energy metabolism. Arch Physiol Biochem. 2011;117:64-9.

67. Ventura-Clapier R, Dworatzek E, Seeland U, Kararigas G, Arnal JF, Brunelleschi S, Carpenter TC, Erdmann J, Franconi F, Giannetta E, et al. Sex in basic research: concepts in the cardiovascular field. Cardiovasc Res. 2017;113:711-24.

68. McCarthy MM, Nugent BM. At the frontier of epigenetics of brain sex differences. Front Behav Neurosci. 2015;9:221.

\section{Publisher's Note}

Springer Nature remains neutral with regard to jurisdictional claims in published maps and institutional affiliations.

Ready to submit your research? Choose BMC and benefit from:

- fast, convenient online submission

- thorough peer review by experienced researchers in your field

- rapid publication on acceptance

- support for research data, including large and complex data types

- gold Open Access which fosters wider collaboration and increased citations

- maximum visibility for your research: over $100 \mathrm{M}$ website views per year

At BMC, research is always in progress.

Learn more biomedcentral.com/submissions 